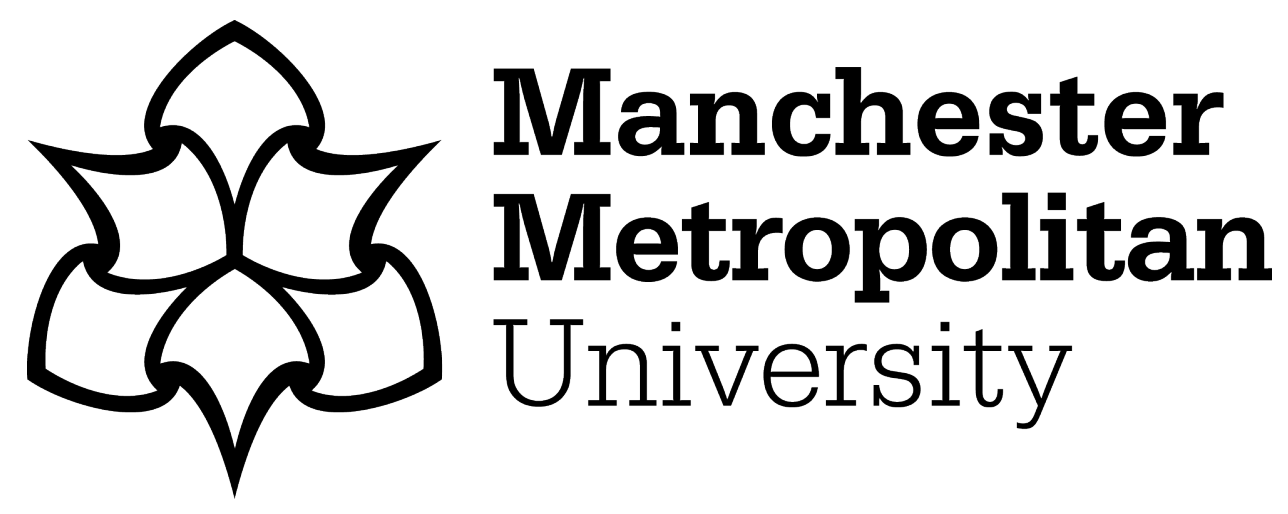

Tan, JP (2018) Do grandparents matter? Intergenerational relationships between the closest grandparents and Malaysian adolescents. Contemporary Social Science, 13 (2). pp. 246-260. ISSN 2158-2041

Downloaded from: https://e-space.mmu.ac.uk/621300/

Version: Accepted Version

Publisher: Taylor \& Francis

DOI: https://doi.org/10.1080/21582041.2018.1424931

Please cite the published version 


\section{Do Grandparents Matter? Intergenerational Relationships between the Closest Grandparents and Malaysian Adolescents}

A close connection with a grandparent can interact with adolescent's experience of life stressors to increase or decrease their risk for negative outcomes. Traditional filial values may be linked to closer grandparent-grandchildren interactions in Asian cultures, such as Malaysia. This study examined how grandparental involvement and emotional closeness moderated the associations between life stressors and adjustment difficulties among adolescents in Malaysia $(n=643$ adolescents). Hierarchical regression analysis showed that greater proximal and distal life stressors were associated with more adjustment difficulties of adolescents. Moreover, emotional closeness with the closest grandparents moderated the association between adolescent distal adversities and adjustment difficulties. Specifically, the contribution of accumulative stress from adverse life events on the risk of adjustment difficulties among adolescents may be alleviated when adolescents perceived high levels of emotional ties with the closest grandparents. These findings suggest that grandparents can directly relate to grandchildren's adjustment through engaging emotional relationships. Our study shed lights on the interpretation of the contribution of grandparent on adolescent outcomes and the development of adolescent's resilience in the face of adversity within the Malaysian cultural context.

Keywords: adolescent adjustment; emotional closeness; grandparental involvement; life adversities 


\section{Introduction}

Past research has recognised that involvement of grandparents can be an important source of support for adolescents, especially during and following significant personal life events or family changes such as parental divorce and remarriage (e.g. AttarSchwartz et al, 2009; Sear \& Coall, 2011). In addition, soaring rates of female workforce participation and dual-earner households has increased parent's difficulties in achieving work-family balance (Higgins, Duxbury \& Lyons, 2010). These factors may lead to greater involvement from extended family members, and in particular the grandparents. In recent decades a changing population structure resulting from increased life-expectancy and decreased birth-rate has characterised many Asian societies, including Malaysia (Demeny 2004). These demographic changes have increased the duration of grandparenthood and the probability of older generations being more involved in their grandchildren's lives as compared to past generation (Buchanan, 2017).

Collectivistic societies in Asia, including Malaysia, emphasise traditional family values that include filial piety, family interdependence, child obedience and respect for older people (Schwalb \& Hossain, 2017). which also reported greater crossgenerational interaction and grandparental involvement in the grandchildren's lives (Chen, Liu, and Mair 2011). While the different ethnic groups in Malaysia share many similarities, adolescents of the Malay, Chinese and Indian ethnic backgrounds may experience subcultural variation in the relationship quality and extent of involvement from grandparents (Thambiah, 2016). Thus the present study examined the possible correlates of intergenerational relationships between adolescents and their grandparents in the multi-ethnic society of Malaysia. 


\section{Grandparenthood in Malaysia}

Based on the 2015 Malaysia Census, the increase in life expectancy to 74.8 years (from 68.0 in 1980) and population's median age to 27.8 years (from 19.5 in 1980) has implied a growing proportion of grandparents and a shrinking proportion of younger children in the society (Antonucci, Jackson \& Biggs, 2007). Hamid \& Nurizan, (2008) report that $48 \%$ of people aged 60 years or over in Malaysia were currently residing with at least one grandchild. Thus, these demographic shifts may facilitate greater possibilities for meaningful and supportive relationships between grandparent and grandchildren (Attar-Schwartz \& Buchanan, 2011).

Grandparenthood is socially constructed and its role may change depending on the needs of the family and of society (Buchanan, 2017). With emerging new types of family arrangements (i.e., "sandwich families" and commuter families), growing numbers of dual-earner households and higher rates of family breakdown, grandparents may represent a source of kin support in time of need (e.g., Lee \& Gardner, 2010; Tan et al., 2010). For example, grandparents in Malaysia often reported active involvement in care-taking of grandchildren after parent's divorce or separation, financial difficulties, or parent's job relocation (Aziz, 2007). More importantly, the unique contribution of grandparents in Asian societies has been recognised, whereby elderly parents play an increasingly significant and integral role in downward support to their children and grandchildren (Butts, et al., 2012; Tsai, Motamed, Elia, \& Rougemont, 2011). Therefore, the potential importance of intergenerational relationships for the development of family and grandparents' role in adolescent adjustment is becoming increasingly recognised within the Malaysian context.

Malaysia is a multicultural society comprising $68 \%$ Malays, $24 \%$ Chinese and 7\% Indians (Department of Statistics Malaysia, 2015). The socio-contextual variance across the three major ethnic groups may create subcultural variation in grandparental 
roles and types of involvement in grandchildren's lives (Chai \& Hamid, 2015; Yusuf, 2014; Tan \& Ibrahim, 2011). For example, the Chinese population, which has the longest life expectancy and is more urbanised may have a greater probability of high levels of grandparenthood as well as better 'access' to adult children compared to Malays and Indians.

Within the limited research on the role of grandparents in Malaysia, grandparents are often described as a source of socio-cultural wisdom and family stability (David, 2008; Yusuf, 2014). Again, there are also differences based on ethnicity. For example, Malaysian Sikh grandparents have found to take several roles: 'teacher' and 'defender' of social, cultural and religious values, 'care-taker' and 'friend' in adolescent lives (David, 2008). Moreover, Chinese grandparents have been found to be more involved in grandchildren's education as compared to Malay and Indian grandparents (Yusuf, 2014). These findings are in agreement with Tan and Ibrahim's study (2011) that showed Chinese grandparents were more concerned about grandchildren's education and Malay grandparents were more involved in social activities with grandchildren. Non-Muslim grandparents also put more emphasis on grandchildren's education as compared to Muslim grandparents (Yusuf, 2014). Although grandmothers are often actively involved in caregiving across cultures, there are some specific gender differences to consider. For example, grandfathers were more likely than grandmothers to engage in cultural and religious aspects of 'educating' grandchildren that include passing down cultural values, language and, religious practices (Yusuf, 2014).

\section{Grandparents and adolescent adjustment difficulties}

Adolescence is a developmental period often characterized by major transitions in social roles and high levels of stress (Wigfield, Byrnes, \& Eccles, 2006), which may lead to 
social and emotional challenges among adolescents. Many risk factors (e.g. poverty, parental divorce/separation, death) have been identified as having a negative impact on adolescents, linking to mental health problems (Copeland et al. 2009), behavioural difficulties (Van der Laan et al. 2010), and poor academic outcomes (Sameroff et al.1998). Cumulative effects of multiple risks have the most negative effects on adjustment of adolescents (Sameroff et al., 1993; Fergusson \& Horwood, 2003). For example, studies show that experiencing an accumulation of adverse life events (e.g., negative change in parents' financial situation or someone in the family dying) has been associated with increased emotional distress and conduct problems for adolescents (Flouri \& Kallis 2007). Further, the impact of cumulative family risk factors on adolescents' adjustment was found to be as great in two-parent families as it was in single-parent families (Sameroff et al. 1998).

However, from the family perspective, a close relationship with a significant non-parental family member (i.e. grandparent) is perceived to have potential benefits in promoting resilience and better adjustment among adolescents, especially in adverse situations (Beam, Chen \& Greenberger, 2002). For example, Flouri and colleagues (2010) found that adolescents' reports of greater emotional connectedness with grandparents were associated with reduced accumulative life stress and, lower psychological difficulties among adolescents. Thus, the potential advantage of the grandparent-grandchild relationship on adolescent development during times of adversities warrants further exploration, especially within non-western cultural context (Attar-Schwartz \& Buchanan, 2011).

The body of literature has highlighted the unique contribution of grandparentsgrandchildren relationships on adolescent's well-being, although the very recent evidence indicates that the "grandparental effect" may not be causal (Tanskanen \& 
Danielsbacka, 2017). In addition, the prior studies are based predominantly on White, Western, ethnically and racially homogenous samples in the U.S. and the U.K (e.g. Attar-Schwarts et al, 2009; Ruis \& Silversterin, 2007). Whereas prior cross-cultural research focuses on narrative and qualitative approach, there is limited empirical evidence from quantitative cross-cultural studies. For example, a study in South Africa found that more involvement from grandparents in the adolescents' lives was linked with positive prosocial behaviour among adolescents (Profe \& Wild, 2015). A study of Israeli adolescents showed that when there is an emotionally closer relationship between parents and adolescents, an emotionally closer relationships with grandparents was associated with better psychological well-being in children (Attar-Schwartz, 2015). However, there is still very little attention given to the cultural context of grandparentgrandchildren relationships (with the exception of Attar-Schwartz \& Khoury-Kassabri, 2016; Wild \& Gaibie, 2014). Thus, this study aims to fill this gap by presenting data on intergenerational ties and their effect on adolescent's lives within an Asian cultural context.

The present study is guided by Bengston and Robert's (1991) intergenerational solidarity framework, which postulated that positive interactions between family members may facilitate more conducive familial relationships. The affectual solidarity, which refers to the positive feelings between family members, can serve as a mechanism that promotes positive grandparent-grandchild relationships and contributes to the development of psychological well-being (Yorgason et al, 2011). In addition, from the family system perspective (Lussier et al, 2002), relationships with multiple family members is strongly emphasised as being important for facilitating a further understanding of child development. Therefore, to understand the relationships with other family members, which extend beyond the exclusive parent-child relationship, 
grandparents should be taken into account as critically important members of these family systems (Lussier et al, 2002; Minuchin, 2002). Thus, the present study utilises these perspectives by examining grandparent-grandchild, emotional closeness and grandparent's involvement in the lives of the adolescents and their contribution to adolescent adjustment.

The main purpose of the present study is to examine how grandparentgrandchild relationships are associated with adolescent experience of life stressors and adjustment difficulties. In specific, it investigates (1) how life stressors (as assessed by the number of proximal and distal adverse life events experienced) relate to adolescent's adjustment difficulties; (2) whether the level of involvement of and emotional closeness with the closest grandparent are associated with life stressors and adjustment difficulties among adolescents; (3) whether grandparent-grandchild relationships moderate the associations between life stressors and adjustment difficulties of adolescents of multicultural background in Malaysia.

\section{Methods}

\section{Participants and procedure}

Secondary school adolescents aged 13 to 17 years old, from Malay, Chinese and Indian ethnic backgrounds, were recruited to the study. Based on a quantitative survey approach, adolescents were selected using Probability Proportional to Size (PPS) cluster sampling technique using a boost for Chinese and Indian adolescents to ensure that adolescents from these groups had a greater chance of being selected. The study sample comprised 643 adolescents, drawn from 15 schools in the central zone of Peninsular Malaysia. Information was collected anonymously, using structured questionnaires which were administered in a classroom setting. Confidentiality was assured to the adolescents who 
provided informed consent to take part. The study obtained ethical approval from the researcher's University Ethical Committee Board.

\section{Instruments}

This study focuses on the adolescents' relationship with grandparents that they felt closest to (refer as the closest grandparents) and the correlates of that relationship. Therefore, the analyses of the adolescent-grandparent relationship below refer to the closest grandparents.

\section{Life stress}

Life stress was assessed with Tiet and colleagues' (1998) adverse life events scale, which measures both proximal life stress (number of adverse life events experienced in the last year, $\alpha=0.72$ ) and distal life stress (number of adverse life events experienced before the last year, $\alpha=0.74$ ). This 25 -item scale is a modification of the life events checklist (LEC; Coddington 1972a, 1972b), which is composed of 25 possible events over which adolescents have little or no control. Higher scores reflect higher levels of life stress experienced by adolescents.

\section{Adjustment difficulties}

Adolescents' adjustment difficulties were assessed by the difficulties domains in the Strengths and Difficulties Questionnaire (SDQ), a 20-item 3-point Likert-type scale, measuring four difficulties (hyperactivity, emotional symptoms, conduct problems, and peer problems) (Goodman, 1994; 1997). A total adjustment difficulties score is calculated by summing the scores for externalizing (i.e. hyperactivity and conduct problems) and internalizing (i.e. emotional symptoms, and peer problems) difficulties ( $\alpha$ $=0.69)$. 
Emotional closeness with the closest grandparent

The emotional closeness between adolescents and all their living grandparents was assessed with the Elder and Conger's (2000) Grandparent-Grandchild Relationship scale. Adolescents reported on the quality of this relationship(s) withal living grandparents on a 4-point Likert scale by indicating the extent to which: they could depend on their grandparents; , they felt appreciated, loved or cared for by them; they were happy with their relationship; the grandparent helped them in significant ways; they were close compared to other grandchildren to grandparents. Scores ranged from $1=$ not at all to $4=a$ lot . The total score for each living grandparent were averaged with higher mean scores indicating a closer grandchild-grandparent relationship.

The grandparents who received the highest averaged score were referred to as the 'closest grandparent' for the adolescents. In 240 cases (37\% of the sample) two or more grandparents shared the highest scores. Following Elder and King's example (2000), in these cases one grandparent was selected as the closest based on either : frequency of contact (i.e., the grandparent that they saw or talked to most as the closest) and/or grandparent's gender (i.e., the same-sex grandparent as the closest). Cronbach's alpha of the scale for the closest grandparent was 0.74 .

\section{Grandparental involvement}

Adolescent reported on the extent to which their grandparents had looked after them, participated in their social interests and school-related activities, had been mentor/advisor for future plans and problems, provided financial assistance and respected by indicating on a 3-point Likert-type scale (ranging from $1=$ never to $3=$ usually; Elder \& Conger, 2000; King \& Elder, 1997). A total score is calculated by summing the scores for these items, with higher scores indicating higher levels of grandparent involvement $(\alpha=0.69)$. 
Demographic information for the adolescents included: age, gender, School Assistance Scheme (SAS) eligibility (in Malaysia, SASs are given to low income families and a proxy for family SES status), ethnicity, and whether they had ever been subject to disciplinary action at school (i.e. disciplined, suspended or expelled). Characteristics of the closest grandparent was reported by the adolescents: age $(1=$ younger than 50 to $4=$ over 70$)$, sex, lineage $(1=$ maternal, $0=$ paternal $)$, health $(1=$ very poor to $4=$ very good), and frequency of contact $(1=$ never to $4=$ daily). The distribution on control variables is presented in the Table 1.

\section{Data analysis}

Pearson correlational analysis and Analysis of variance (ANOVA) was computed to examine relations and ethnicity differences in the intergenerational relationships and adjustment difficulties.

Next hierarchical regression analysis was used to examine whether life stress and, outcome measures for intergenerational relationships were associated with adolescent's' adjustment difficulties. In the first step, the selected socio-demographics characteristics of the adolescents were entered as control variables. The second step included the adolescent's proximal and distal adversities. This was followed by intergenerational relationships variables, including emotional closeness and involvement of the closest grandparent. Finally, interaction terms of life stress (i.e. proximal and distal adversities) and intergenerational relationships (emotional closeness and involvement of the closest grandparents) were added. 


\section{Results}

\section{Descriptive statistics}

As can be seen in table 1, the majority of the closest grandparents were grandmothers: $45 \%$ were maternal and $31 \%$ were paternal grandmothers and, the rest were grandfathers (16\% maternal and $9 \%$ paternal). Just over half of the closest grandparents were in their $70 \mathrm{~s}(56 \%)$ and two thirds were reported to be in good health. The score for frequency of contact between adolescent and the closest grandparents averaged at 2.67 on a scale ranging from 1 (never) to 4 (daily) $(\mathrm{SD}=0.81)$. The average score for grandparental involvement was $13.25(\mathrm{SD}=2.68)$ on a scale ranging from 7 to 21 and the score for emotional closeness to the closest grandparent averaged at 2.84 on a scale ranging from 1 to $4(\mathrm{SD}=0.66)$.

\section{Ethnic comparison}

As shown in Table 2, no significant difference was found in the levels of adolescents' adjustment difficulties according to ethnic group. However, the mean scores for adolescents' proximal and distal adversities were significantly different between adolescents from different ethnic backgrounds, as were the quality of intergenerational relationships. Specifically, Chinese adolescents reported lower levels of emotional closeness to, and involvement of, their closest grandparent; they also reported higher levels of proximal adversities compared to those of Malay and Indian ethnic backgrounds.

\section{Bivariate analysis}

Table 3 shows that higher levels of adjustment difficulties were reported by older adolescents, those with greater life stress from both proximal and distal life adversities 
and those with lower levels of emotional closeness to and involvement from their closest grandparent.. Emotional closeness to the closest grandparent was higher among boys and among those who reported a greater extent of grandparental involvement. Adolescents who reported higher levels of proximal and distal adversities also reported a less emotionally close relationship with their grandparent. Malay adolescents were more likely to report greater proximal and distal life adversities than those in the other ethnic group.

\section{Hierarchical Regression: the moderating role of intergenerational relationships in the link between life stress and adjustment difficulties}

As presented in Table 4, after controlling for adolescent's gender, ethnicity, family type and SES status (with eligibility for SAS as proxy), greater stress experienced from both proximal and distal life adversities was related to increased psychological difficulties among adolescents (Model 1). However, after controlling for adolescent's life stress in Model 2, grandparental involvement and intergenerational emotional closeness were no longer significantly associated with adjustment difficulties as showed in the results from correlational analysis in Table 2.

In the next step, hierarchical regression analysis was used to test the moderating effect of emotional closeness and involvement of the closest grandparent in the relations between life stress and adjustment difficulties. It was shown that only the interaction term that was statistically significant in predicting adolescent adjustment was the interaction between distal life adversities and emotional closeness to the grandparent.

As illustrated in Figure 1, the results from the probing analysis revealed that the positive association between adolescent's distal life adversities and adjustment difficulties was significant only at mean and high levels of emotional closeness with the closest grandparents $\left(\beta_{\text {mean }}=0.26, p<.001\right.$, and $\beta_{\text {high }}=0.27, p<.001$, 
respectively). When the adolescents reported low levels of perceived emotional closeness to the closest grandparents, the association between adolescent's experience of distal life adversities and adjustments was not statistically significant. These results indicate that the contribution of accumulative stress from multiple life events on the risk of adjustment difficulties may be alleviated when adolescents perceived a strong emotional relationship with the closest grandparents.

The examination of whether the moderating effect of intergenerational relationships differed according to adolescents' ethnic background yielded some consistent findings. Results showed that the contribution of ethnicity in the regression equation of life stress, grandparent-grandchild relationships and interaction terms of these variables remain insignificant in all regression models. In other words, the role of emotional closeness in buffering the risk of distal life adversities on adolescents' adjustment difficulties is equally important for all adolescents irrespective of ethnic background in the present study.

\section{Discussion}

The current study adds to the emerging line of research on the contribution of intergenerational ties on adolescent outcomes by examining the adolescents' adjustment difficulties in the context of grandparent-grandchild relationships and life stress among a sample of adolescents in multicultural Malaysia. Findings showed that two aspects of grandparent-grandchild relationship (emotional closeness and grandparental involvement), were related to lower levels of psychological difficulties for adolescents. Thirdly, while, higher levels of emotional closeness with the closest grandparent was related to lower levels of life stress among adolescents, active involvement of the closest grandparents was not. The main findings demonstrated that emotional closeness to the closest grandparents moderated the relationship between adolescents' distal life 
adversities and adjustment difficulties. Specifically, the findings showed that when adolescents perceived high levels of emotional closeness to their closest grandparent, the positive association between adolescents' distal life adversities and adjustment difficulties was weakened. Finally, within a multi-cultural context, the role of emotional closeness in buffering the risk of life stressors on adolescent's psychological difficulties was also consistent for adolescents from different ethnic backgrounds. These findings stress the importance of investigating the unique contribution that grandparents may have on adolescents' adjustment in the context of life adversities.

The positive association between life stressors from both proximal and distal adversities and adolescents' adjustments difficulties was in line with prior research showing that greater exposure to the conditions of risk and adversities were associated with poorer functioning of adolescents (Day, Ji, DuBois, Silverthorn \& Flay, 2017). It also showed that adolescents with higher levels of perceived emotional closeness to, and involvement from, their closest grandparent reported lower levels of adjustment difficulties. These findings support those studies conducted in the UK, USA, South Africa and Israel in which better grandparent-grandchild relationships were linked with fewer adjustment difficulties and better prosocial behaviour among adolescents (AttarSchwartz \& Fuller-Thomson, 2017; Griggs et al 2011; Levetan \& Wild, 2015; Yorgason et al., 2011). Finally, while stronger emotional closeness with the closest grandparent was related to lower levels of life stress among adolescents, active grandparental involvement was not significantly related to adolescents life stress experience. This may imply that the diverse aspects of intergenerational ties relate differently to the experience of life stressors in so far as emotional ties and affectual feelings appear to be more relevant for better adolescent adjustment than instrumental or action-oriented support.(Demaray, 2003; Griffiths, Crisp, Barney \& Reid, 2011). This may warrant 
further investigation on the contribution of different aspects of grandparent-grandchild relationships on adolescent well-being within the context of accumulative risk and life stressors.

Emotional closeness to the closest grandparents moderates the relationship between adolescent's distal life adversities and adjustment difficulties. The findings showed that the positive link between adolescent's distal life adversities and adjustment difficulties was weaker when there is a close grandparent-grandchild emotional tie. This is consistent with previous research, which showed that closeness to the most significant grandparent moderated the effect of life stress on broad and specific psychopathology among adolescents (Flouri et al., 2010). These findings indicate that one should view the child within the context of his or her larger family system, rather than focusing exclusively on the child-parent bond (Lussier et al. 2002).

While there were cultural variations in the extent of intergenerational relationship, the role of emotional closeness in decreasing the risk of life stressors on adolescent's adjustment difficulties was found to be consistent across ethnic groups in Malaysia. This finding is in contrast with some others (e.g., Attar-Schwartz, 2017), who have documented cultural variations in the adolescent-grandparent relationships and the extent that adolescents may benefit from them. A plausible explanation may be the emphasis of the present study on the association between adverse life experience and adolescent functioning. Prior research has documented the greater significance for grandparent's role among individual or families during time of transition (Ruiz \& Silverstein, 2007) and among adolescents from step- and blended-families as compared to those in two-biological families (see Attar-Schwartz et al, 2009).

The current findings should be interpreted cautiously given the study's limitations. First, the study was based on a cross-sectional research design and 
therefore, we were not able to infer any causal relationship between intergenerational relationships, life stress and adjustment difficulties among adolescents. Longitudinal data would provide possibilities to further examine the dynamics of these variables and understand how the grandparent-grandchild relationships develop over time and how that contribute to adolescents' well-being. Second, adolescents were the sole informant for the present study, which increases the possibility of same-reporter bias. Future studies would benefit from a multi-informant assessment approach. For example, the teacher's report on psychological adjustments of adolescents may reduce the probability of self-report bias by alleviating under- or over-reporting. Responses from grandparents may also capture their distinctive perspective on intergenerational ties. Future research should replicate this study among representative sample from each of the major ethnic groups like Malay, Chinese and Indians and, covering a larger geographical area to enhance the generalisability of the study's findings. Future study should focused on the adolescents' emotionally closest grandparents rather than all living grandparents when gathering information on the unique contribution of the 'closest' grandparent on adolescent adjustment. Finally, future studies should consider the examination of the two aspects of intergenerational ties, namely the emotional closeness (affective feelings) and grandparent involvement (behaviour/action) separately to get a sense of how the different aspects of grandparent-grandchild relationships are related to adolescents' well-being at the time of adversities.

Despite the limitations, the present study adds to current knowledge regarding intergenerational relationships between grandparents and grandchildren and adolescent psychological adjustment. Findings from this study emphasise the need to take into consideration the role of grandparents in the association between emotional closeness and adolescent adjustment. Although the current study cannot determine causal 
implications, these findings may indicate that Malaysian grandchildren, irrespective of ethnic background, could be the beneficiaries of a close relationship with grandparents. This study highlighted a close emotional relationship with grandparents as a potential resource for support among all adolescents in general (Attar-Shalhavet et al 2009) and, in particular, for buffering the potential impact from accumulative risk factors on the psychological functioning of adolescents. Such findings call for policy makers, public institutions and practitioners to adopt an ecological approach towards policies and interventions with adolescents, rather than exclusively focusing on the parents or nuclear families in relation to adolescent well-being, development and family functioning.

Acknowledgements: This project was funded by the University of Putra Malaysia's Resource Management Centre Grant (RMC) for the Intergenerational Relationships and Adolescent Psychological Adjustment project. 


\section{References}

Antonucci, T. C., Jackson, J. S., \& Biggs, S. (2007). Intergenerational relations: Theory, research, and policy. Journal of Social Issues, 63(4), 679-693.

Attar-Schwartz, S. \& Buchanan, A. (2011). Grandparent-adolescent relationships. In R. J. R. Levesque (Ed.), Encyclopaedia of adolescence (pp.1213-1225), New York, NY: Springer.

Attar-Schwartz, S., (2017). Grandfathering and Adolescent Adjustment Difficulties and Pro-social Behaviour Among Israeli Jewish and Arab Adolescents. In A. Buchanan \& Rotkirch, A (Eds), Grandfathers (pp. 267-284). Palgrave Macmillan UK.

Attar-Schwartz, S. (2015). Emotional closeness to parents and grandparents: A moderated mediation model predicting adolescent adjustment. American Journal of Orthopsychiatry, 85(5), 495.

Attar-Schwartz, S., \& Fuller-Thomson, E. (2017). Adolescents' closeness to paternal grandmothers in the face of parents' divorce. Children and Youth Services Review, 77, 118-126.

Attar-Schwartz, S., \& Khoury-Kassabri, M. (2016). The moderating role of cultural affiliation in the link between emotional closeness to grandparents and adolescent adjustment difficulties and prosocial behavior. American Journal of Orthopsychiatry, 86(5), 564.

Attar-Schwartz, S., Tan, J. P., \& Buchanan, A. (2009). Adolescents' perspectives on relationships with grandparents: The contribution of adolescent, grandparent, and parent-grandparent relationship variables. Children and Youth Services Review, 31(9), $1057-1066$. 
Attar-Schwartz, S., Tan, J. P., Buchanan, A., Flouri, E., \& Griggs, J. (2009).

Grandparenting and adolescent adjustment in two-parent biological, lone-parent, and step-families. Journal of family psychology, 23(1), 67.

Aziz, R. A. (2007). Grandparenting: Issues and challenges. Akademika, 70, 103-116.

Beam, M. R., Chen, C., \& Greenberger, E. (2002). The nature of adolescents'

relationships with their "very important" nonparental adults. American journal of community psychology, 30(2), 305-325.

Bengtson, V. L., \& Roberts, R. E. (1991). Intergenerational solidarity in aging families: An example of formal theory construction. Journal of Marriage and the Family, 856870.

Brand, A. H., \& Johnson, J. H. (1982). Note on reliability of the Life Events Checklist. Psychological Reports.

Buchanan, A. (2017). Changing roles of Grandparents in the UK: Emergence of the 'New' Grandfather. In D. Shwalb \& Hossain, Z. (Eds) Grandparents in cultural context. New York: Routledge.

Buchanan, A., \& Flouri, E. (2008). Involved grandparenting and child well-being. Full Research Report ESRC End of Award Report, RES-000-22-2283.

Butts, D., Thang, L. L., Yeo, A. H., \& Jefferson, T. (2012). Policies and programmes supporting intergenerational relations. Background paper. UNDESA, New York. Chai, S. T. \& Hamid, T.A. (2015). Population Ageing and the Malaysian Chinese: Issues and Challenges. Malaysian Journal of Chinese Studies, 4 (1), 1-13. Chen, F., Liu, G., \& Mair, C. A. (2011). Intergenerational ties in context: Grandparents caring for grandchildren in China. Social Forces, 90(2), 571-594. 
Coddington, R. D. (1972a). The significance of life events as etiologic factors in the diseases of children-II a study of a normal population. Journal of psychosomatic research, 16(3), 205-213.

Coddington, R. D. (1972b). The signifance of life events as etiologic factors in the diseases of children. I. A survey of professional workers. Journal of psychosomatic research, 16(1), 7-18.

Copeland, W. E., Shanahan, L., Costello, E. J., \& Angold, A. (2009). Childhood and adolescent psychiatric disorders as predictors of young adult disorders. Archives of general psychiatry, 66(7), 764-772.

Creasey, G. L., \& Koblewski, P. J. (1991). Adolescent grandchildren's relationships with maternal and paternal grandmothers and grandfathers. Journal of adolescence, 14(4), 373-387.

David, M. K. (2013). Roles of Sindhi Grandparents in Malaysia. In Indian Diaspora (pp. 125-137). Rotterdam: SensePublishers.

Day, J., Ji, P., DuBois, D. L., Silverthorn, N., \& Flay, B. (2016). Cumulative socialenvironmental adversity exposure as predictor of psychological distress and risk behavior in urban youth. Child and adolescent social work journal, 33(3), 219-235. Demaray, M. K., \& Malecki, C. K. (2003). Perceptions of the frequency and importance of social support by students classified as victims, bullies, and bully/victims in an urban middle school. School Psychology Review, 32(3), 471-490.

Demeny, Paul (2004). Developing Economic Support Systmes for the Old-age Population in Asia: Learning from the Mistakes of Western Welfare States. Paper published as part of the International Conference on the Demographic Window and Healthy Aging: Socioeconomic Challenges and Opportunities. Beijing, 10th to 11th, 2004. 
Department of Statistics Malaysia (2013). Characteristics of Household 2010.

Population and Housing Census of Malaysia. DOSM: Putrajaya.

Department of Statistics Malaysia (2015). Current Population Estimates, 2015. DOSM:

Putrajaya.

Elder, G. H., \& King, V. (2000). Wisdom of the ages. In G. H. Elder \& R. D. Conger (Eds.), Children of the land: Adversity and success in rural America (pp. 127-150).

Chicago, IL: University of Chicago Press.

Elder, G. H., Jr., \& Conger, R. D. (2000). Children of the land: Adversity and success in rural America. Chicago: University of Chicago Press.

Fergusson, D. M., \& Horwood, L. J. (2003). Resilience to childhood adversity: Results of a 21-year study. Resilience and vulnerability: Adaptation in the context of childhood adversities, 130-155.

Flouri, E., \& Kallis, C. (2007). Adverse life events and psychopathology and prosocial behavior in late adolescence: testing the timing, specificity, accumulation, gradient, and moderation of contextual risk. Journal of the American Academy of Child \& Adolescent Psychiatry, 46(12), 1651-1659.

Flouri, E., Buchanan, A., Tan, J. P., Griggs, J., \& Attar-Schwartz, S. (2010). Adverse life events, area socio-economic disadvantage, and adolescent psychopathology: The role of closeness to grandparents in moderating the effect of contextual stress. Stress, 13(5), 402-412.

Goodman, A., \& Goodman, R. (2009). Strengths and difficulties questionnaire as a dimensional measure of child mental health. Journal of the American Academy of Child \& Adolescent Psychiatry, 48(4), 400-403.

Goodman, R. (1994). A modified version of the Rutter parent questionnaire including extra items on children's strengths: A 
Goodman, R. (1997). The Strengths and Difficulties Questionnaire: A research note. Journal of Child Psychology and Psychiatry, 38, 581-586.

Griffiths, K. M., Crisp, D. A., Barney, L., \& Reid, R. (2011). Seeking help for depression from family and friends: A qualitative analysis of perceived advantages and disadvantages. BMC Psychiatry, 11(1), 196.

Griggs, J., Tan, J. P., Buchanan, A., Attar-Schwartz, S., \& Flouri, E. (2010). 'They’ve Always Been There for Me': Grandparental Involvement and Child WellBeing. Children \& Society, 24(3), 200-214.

Hamid, T. A. \& Nurizan, Y. (2008). National Policy for the elderly in Malaysia: Achievement and challenges. In Lee, H. G. (Eds). Ageing in Southeast and East Asia: Family, Social Protection \& Policy Challenges (pp. 108-133), Singapore: Institute of Southeast Asian Studies.

Hawes, D. J., \& Dadds, M. R. (2004). Australian data and psychometric properties of the Strengths and Difficulties Questionnaire. Australian and New Zealand Journal of Psychiatry, 38(8), 644-651.

Henderson, C. E., Hayslip Jr, B., Sanders, L. M., \& Louden, L. (2009). Grandmothergrandchild relationship quality predicts psychological adjustment among youth from divorced families. Journal of Family Issues, 30(9), 1245-1264.

Higgins, C. A., Duxbury, L. E., \& Lyons, S. T. (2010). Coping With Overload and Stress: Men and Women in Dual-Earner Families. Journal of Marriage and Family, 72(4), 847-859.

Lee, M., \& Gardner, J. E. (2010). Grandparents' involvement and support in families with children with disabilities. Educational Gerontology, 36(6), 467-499. 
Lussier, G., Deater-Deckard, K., Dunn, J., \& Davies, L. (2002). Support across two generations: children's closeness to grandparents following parental divorce and remarriage. Journal of Family Psychology, 16(3), 363.

Minuchin, P. (2002). Looking toward the horizon: Present and future in the study of family systems. Retrospect and prospect in the psychological study of families, 259278.

Monserud, M. A. (2008). Intergenerational relationships and affectual solidarity between grandparents and young adults. Journal of Marriage and Family, 70(1), 182195.

Pala, J. (2005). Population Ageing Trends in Malaysia, Population Census 2000 Monograph Series, No.1. DOSM: Putrajaya.

Profe, W., \& Wild, L. G. (2017). Mother, father, and grandparent involvement: Associations with adolescent mental health and substance use. Journal of Family Issues, 38(6), 776-797.

research note. Journal of Child Psychology and Psychiatry, 35, 1483-1494.

Ruiz, S. A., \& Silverstein, M. (2007). Relationships with grandparents and the emotional well-being of late adolescent and young adult grandchildren. Journal of Social Issues, 63(4), 793-808.

Sameroff, A. J., \& Mackenzie, M. J. (2003). Research strategies for capturing transactional models of development: The limits of the possible. Development and psychopathology, 15(3), 613-640.

Sameroff, A. J., Bartko, W. T., Baldwin, A., Baldwin, C., \& Seifer, R. (1998). Family and social influences on the development of child competence. 
Sameroff, A. J., Seifer, R., Baldwin, A., \& Baldwin, C. (1993). Stability of intelligence from preschool to adolescence: The influence of social and family risk factors. Child development, 64(1), 80-97.

Shwalb, D. W., \& Hossain, Z. (Eds.). (2017). Grandparents in Cultural Context. Routledge.

Sear, R., \& Coall, D. (2011). How much does family matter? Cooperative breeding and the demographic transition. Population and development review, 37(s1), 81-112.

Tan, J. P., Buchanan, A., Flouri, E., Attar-Schwartz, S., \& Griggs, J. (2010). Filling the parenting gap? Grandparent involvement with UK adolescents. Journal of Family Issues, 31(7), 992-1015.

Tan, J-P \& Rahimah, Ibrahim (2011). Intergenerational Relationships: Grandparental Involvement, Care and Social Exchange among Multicultural families in Malaysia, conference paper presented at the Shifting Boundaries of Care Provision in Asia, March 14-15, 2011, Asia Research Institute (ARI), National University of Singapore, Singapore.

Tanskanen, A.O. \& Danielsbacka, M. (2017). Multigenerational effects on children's cognitive and socioemotional outcomes. A within-child investigation. Child Development, 88, doi:10.1111/cdev.12968.

Thambiah, S. (2016). Gender in Southeast Asia a fluid, contested and negotiable conceptual field.

Tiet, Q. Q., Bird, H. R., Davies, M., Hoven, C., Cohen, P., Jensen, P. S., \& Goodman, S. (1998). Adverse life events and resilience. Journal of the American Academy of Child \& Adolescent Psychiatry, 37(11), 1191-1200.

Tsai, F. J., Motamed, S., Elia, N., \& Rougemont, A. C. (2011). Evolution in intergenerational exchanges between elderly people and their grandchildren in Taiwan; 
data from a multiple round cross-sectional study from 1993 to 2007. BMC public health, 11(1), 639.

van der Laan, A. M., Veenstra, R., Bogaerts, S., Verhulst, F. C., \& Ormel, J. (2010). Serious, minor, and non-delinquents in early adolescence: The impact of cumulative risk and promotive factors. The TRAILS study. Journal of abnormal child psychology, 38(3), 339-351.

Wigfield, A., Byrnes, J. P., \& Eccles, J. S. (2006). Development during early and middle adolescence. Handbook of educational psychology, 2, 87-113.

Wild, L. G., \& Gaibie, F. (2014). Grandparental involvement and South African adolescents' psychological well-being. Journal of Intergenerational Relationships, 12(4), 425-441.

Woerner, W., Fleitlich-Bilyk, B., Martinussen, R., Fletcher, J., Cucchiaro, G., Dalgalarrondo, P., \& Tannock, R. (2004). The Strengths and Difficulties Questionnaire overseas: evaluations and applications of the SDQ beyond Europe. European child \& adolescent psychiatry, 13, ii47-ii54.

Yorgason, J. B., Padilla-Walker, L., \& Jackson, J. (2011). Nonresidential grandparents' emotional and financial involvement in relation to early adolescent grandchild outcomes. Journal of Research on Adolescence, 21(3), 552-558.

Yusuf, M. (2014). Grandparents as educators: A study of socio-cultural and religion perspectives. Procedia-Social and Behavioral Sciences, 140, 337-342. 
Table 1. Descriptive statistics of adolescents' background characteristics ( $N=643)$

\begin{tabular}{|c|c|c|c|c|}
\hline Variables & Categories & $\begin{array}{c}\text { Frequency, } \\
\mathrm{n}\end{array}$ & $\begin{array}{c}\text { Percentage, } \\
\%\end{array}$ & Mean (SD) \\
\hline $\begin{array}{l}\text { 1. Adolescent's } \\
\text { Age }\end{array}$ & $\begin{array}{l}12-13 \\
14-15 \\
16-17\end{array}$ & $\begin{array}{l}145 \\
277 \\
221\end{array}$ & $\begin{array}{l}22.5 \\
43.2 \\
34.3\end{array}$ & $14.5(1.25)$ \\
\hline $\begin{array}{l}\text { 2. Adolescent's } \\
\text { Ethnicity }\end{array}$ & $\begin{array}{l}\text { Malay } \\
\text { Chinese } \\
\text { Indian }\end{array}$ & $\begin{array}{l}336 \\
154 \\
153\end{array}$ & $\begin{array}{l}52.3 \\
23.9 \\
23.8\end{array}$ & - \\
\hline $\begin{array}{l}\text { 3. Adolescent's } \\
\text { Gender }\end{array}$ & $\begin{array}{l}\text { Male } \\
\text { Female }\end{array}$ & $\begin{array}{l}343 \\
300\end{array}$ & $\begin{array}{l}53.4 \\
46.6\end{array}$ & - \\
\hline $\begin{array}{l}\text { 4. Family } \\
\text { structure }\end{array}$ & $\begin{array}{l}\text { Two-biological-parent } \\
\text { Single-parent } \\
\text { Step-parents } \\
\text { Others }\end{array}$ & $\begin{array}{c}541 \\
69 \\
5 \\
28\end{array}$ & $\begin{array}{c}84.2 \\
10.7 \\
0.8 \\
4.3\end{array}$ & - \\
\hline $\begin{array}{l}\text { 5. Eligible for } \\
\text { School } \\
\text { Assistance } \\
\text { Scheme (SAS) }\end{array}$ & $\begin{array}{l}\text { Yes } \\
\text { No }\end{array}$ & $\begin{array}{l}181 \\
462\end{array}$ & $\begin{array}{l}28.2 \\
71.8\end{array}$ & - \\
\hline $\begin{array}{l}\text { 6. Reported } \\
\text { disciplinary } \\
\text { record school }\end{array}$ & $\begin{array}{l}\text { Yes } \\
\text { No }\end{array}$ & $\begin{array}{c}78 \\
565\end{array}$ & $\begin{array}{l}12.1 \\
87.9\end{array}$ & - \\
\hline 7. Life stress & $\begin{array}{l}\text { Proximal Adversities } \\
\text { Distal Adversities }\end{array}$ & - & - & $\begin{array}{l}2.95(2.77) \\
4.41(3.27)\end{array}$ \\
\hline $\begin{array}{l}\text { 8. Adjustment } \\
\text { difficulties }\end{array}$ & $\begin{array}{l}\text { Total difficulties } \\
\text { Externalising } \\
\text { Internalising }\end{array}$ & - & - & $\begin{array}{l}12.6(4.97) \\
6.5(2.96) \\
6.2(2.94)\end{array}$ \\
\hline
\end{tabular}

Note. 'Others' family structure include living with siblings, grandparent, other relatives; Eligibility for SAS = Proxy for Family SES. Total difficulties = Proxy for Adolescent's adjustment difficulties 
Table 2. Comparative analysis of life stress, intergenerational relationships and adolescents' adjustment difficulties according to ethnic background $(\mathrm{N}=643)$

\begin{tabular}{|l|c|c|c|c|}
\hline Variables & $\begin{array}{c}\text { Malay } \\
\text { Mean (SD) }\end{array}$ & $\begin{array}{c}\text { Chinese } \\
\text { Mean }(S D)\end{array}$ & $\begin{array}{c}\text { Indian } \\
\text { Mean }(S D)\end{array}$ & F-value \\
\hline $\begin{array}{l}\text { 1. Proximal } \\
\text { adversities }\end{array}$ & $2.59(3.31)$ & $2.69(3.24)$ & $2.48(2.60)$ & $5.633^{* *}$ \\
\hline $\begin{array}{l}\text { 2. Distal } \\
\text { Adversities }\end{array}$ & $4.82(3.02)$ & $3.83(3.53)$ & $4.14(3.47)$ & $5.75^{* * *}$ \\
\hline $\begin{array}{l}\text { 3. Grandparent } \\
\text { Involvement }\end{array}$ & $13.18(2.65)$ & $12.73(2.63)$ & $13.92(2.69)$ & $7.98^{* * *}$ \\
\hline $\begin{array}{l}\text { 4. Emotional } \\
\text { closeness }\end{array}$ & $2.85(0.64)$ & $2.79(0.63)$ & $3.11(0.68)$ & $11.54^{* * *}$ \\
\hline $\begin{array}{l}\text { 5. Adjustment } \\
\text { difficulties }\end{array}$ & $12.67(4.88)$ & $12.91(4.81)$ & $12.35(5.35)$ & 0.469 \\
\hline
\end{tabular}


Table 3. Pearson correlational analysis of life stress, intergenerational relationships and adolescent adjustment difficulties $(\mathrm{N}=643)$

\begin{tabular}{|l|c|c|c|c|c|c|c|c|c|}
\hline Variables & 1 & 2 & 3 & 4 & 5 & 6 & 7 & 8 & 9 \\
\hline 1. Adolescent's age & - & & & & & & & & \\
\hline 2. Adolescent's gender & $-0.082^{*}$ & - & & & & & & & \\
\hline 3. Adolescent's ethnicity & $-0.158^{* * *}$ & $0.118^{* *}$ & - & & & & & & \\
\hline 4. Family type & $0.158^{* * *}$ & -0.035 & -0.005 & - & & & & & \\
\hline 5. Family SES & -0.069 & 0.025 & $0.212^{* * *}$ & 0.048 & - & & & & \\
\hline 6. Proximal adversities & 0.019 & 0.049 & $0.131^{* * *}$ & 0.015 & 0.018 & - & & & \\
\hline 7. Distal adversities & 0.011 & 0.069 & $0.127^{* * *}$ & 0.054 & $0.079^{*}$ & $0.664^{* * *}$ & - & & \\
\hline $\begin{array}{l}\text { 8. Grandparental } \\
\text { involvement }\end{array}$ & -0.026 & 0.073 & -0.024 & -0.005 & 0.023 & -0.003 & -0.017 & - & \\
\hline 9. Emotional closeness & $-0.096^{*}$ & $0.108^{* *}$ & -0.076 & -0.019 & -0.053 & $-0.083^{*}$ & $-0.093^{*}$ & $0.665^{* * *}$ & - \\
\hline 10. Adjustment difficulties & $0.115^{* *}$ & -0.033 & 0.003 & -0.013 & -0.045 & $0.238^{* * *}$ & $0.264^{* * *}$ & $-0.082^{*}$ & $-0.107^{* *}$ \\
\hline
\end{tabular}

Note: $* \mathrm{p}<.05 ; * * \mathrm{p}<.01 ; * * * \mathrm{p}<.001$ Controlling for Grandchildren Gender (1=Male), Family SES (1=Eligible for SAS) and Family Structure (1=Two-biological parents) 
Table 3. Regression analysis predicting adolescent adjustment difficulties $(\mathrm{N}=643)$

\begin{tabular}{|c|c|c|}
\hline Variable & & $\begin{array}{c}\text { Standardised Co-efficient } \\
(B)\end{array}$ \\
\hline $\begin{array}{l}\text { Background } \\
\text { characteristics }\end{array}$ & $\begin{array}{l}\text { Adolescent gender } \\
\text { Family SES } \\
\text { Family type } \\
\text { Adolescent ethnic (Chinese) } \\
\text { Adolescent ethnic (Indian) }\end{array}$ & $\begin{array}{c}-0.032 \\
-0.051 \\
-0.008 \\
0.012 \\
-0.045 \\
0.006\end{array}$ \\
\hline Life stress: & $\begin{array}{l}\text { Proximal Adversities } \\
\text { Distal Adversities }\end{array}$ & $\begin{array}{c}0.131^{*} \\
0.186^{* * *} \\
0.083 * * *\end{array}$ \\
\hline $\begin{array}{l}\text { Relationships with } \\
\text { closest grandparents: }\end{array}$ & $\begin{array}{l}\text { Grandparental Involvement } \\
\text { Emotional Closeness }\end{array}$ & $\begin{array}{l}-0.040 \\
-0.058 \\
0.008+\end{array}$ \\
\hline $\begin{array}{l}\text { Interaction } \\
\text { Terms: }\end{array}$ & $\begin{array}{l}\text { Proximal X Grandparental Involvement } \\
\text { Proximal X Emotional Closeness } \\
\text { Distal X Grandparental Involvement } \\
\text { Distal X Emotional Closeness }\end{array}$ & $\begin{array}{c}0.091 \\
-0.090 \\
-0.095 \\
0.128^{*}\end{array}$ \\
\hline & $\begin{array}{c}R^{2} \text { change } \\
\text { Adjusted } R^{2}\end{array}$ & $\begin{array}{l}0.007 \\
0.084\end{array}$ \\
\hline
\end{tabular}

Note. + p $<.10,{ }^{*} p<.05, * * p<.01, * * * p<.001$

Controlling for Adolescent Gender ( $1=$ Male, $0=$ Female), Family SES ( $1=$ Eligible for SAS, $0=$ Not eligible for SAS) and Family Structure (1=Two-biological parents, $0=$ Others)

Ethnicity $(\beta)$ : Model 2: Chinese $=0.043$, Indian $=-0.014 ;$ Model 3: Chinese $=0.037$, Indian $=-0.001 ;$ Model 4: Chinese $=0.035$, Indian $=0.002$ 


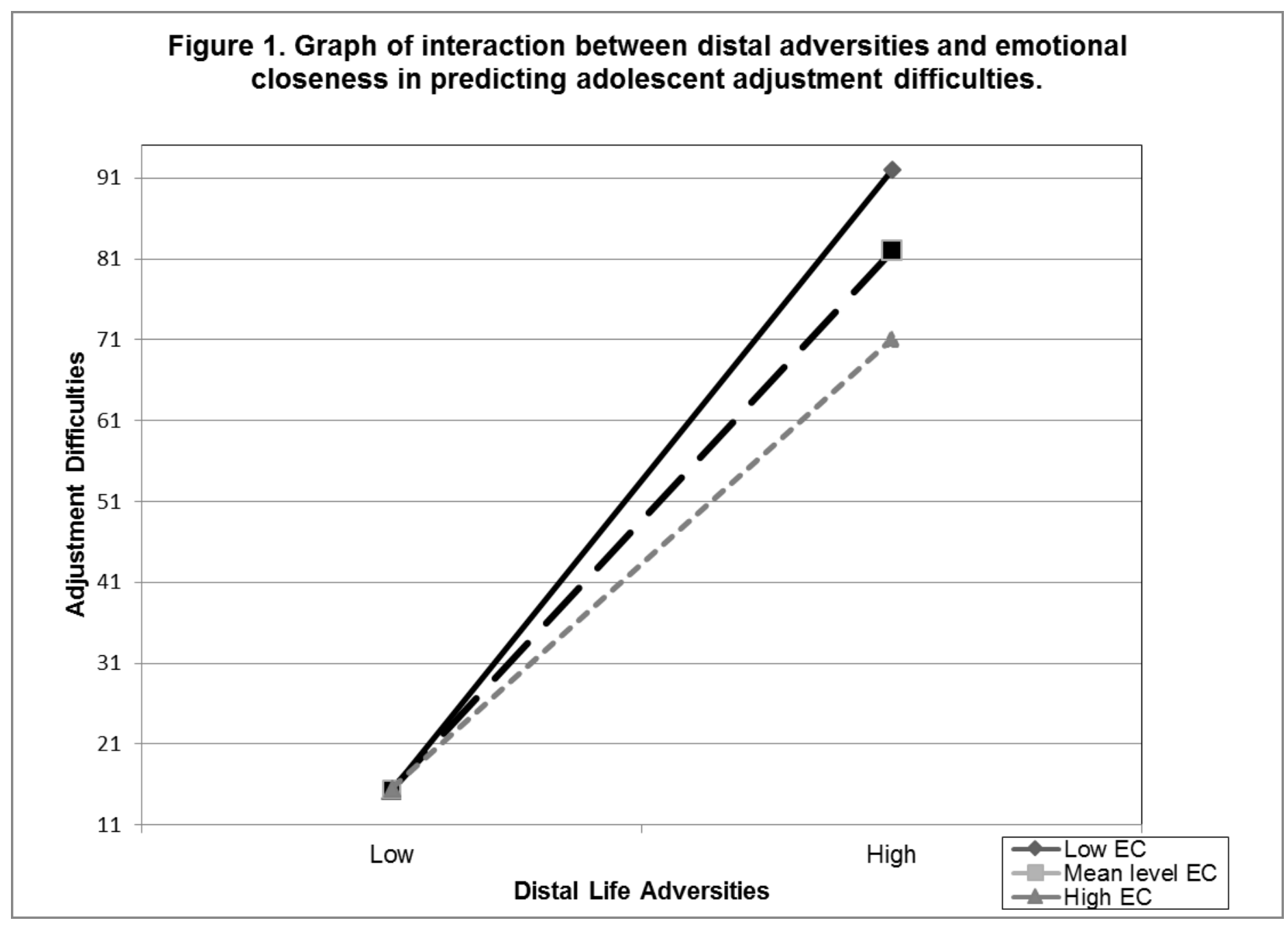

